\title{
Synthesis and Structural Characterization of a Single-Crystal to Single- Crystal Transformable Coordination Polymer
}

\author{
Yuyang Tian, ${ }^{a}$ Phoebe K. Allan, ${ }^{a}$ Catherine L. Renouf, ${ }^{a}$ Xiang He, ${ }^{b}$ Laura J. McCormick ${ }^{a}$ and Russell E. \\ Morris*a \\ ${ }_{5}$ Received (in $\left.X X X, X X X\right)$ Xth $X X X X X X X X X 20 X X$, Accepted Xth XXXXXXXXX 20XX \\ DOI: $10.1039 / b 000000 x$
}

A single-crystal to single-crystal transformable coordination polymer compound was hydrothermally synthesized. The structural rearrangement is induced by selecting a ligand that ${ }_{10}$ contains both strong and weaker coordinating groups. Both hydrated and dehydrated structures were determined by single crystal $X$-ray analysis.

In the last two decades, coordination polymer and Metal-Organic 15 Frameworks have developed into a hot research topic, ${ }^{1-3}$ due to their potential application in areas such as gas adsorption, drug delivery, separation and catalysis. ${ }^{4-11}$ Compared with traditional adsorbents and catalysts including zeolites and molecular sieves, MOFs present many unique properties due to their chemical 20 nature and their intrinsic structures. The network structures of MOF materials are built up by coordinate bonds between organic ligands and metal centres. It is possible, in a way, to target the synthesis of MOF materials with particular structures or properties by carefully selecting and designing the organic 25 ligands. ${ }^{12,13}$

One particularly unusual feature of MOFs is their structural flexibility. This can lead to remarkable effects such as 'breathing, ${ }^{14}$ pore-discriminating adsorption ${ }^{15}$ and reversible single crystal to single crystal transformations. ${ }^{16}$ The latter class

30 of MOF materials responds to external stimuli such as heating or guest exchange and reversible structure transformations can occur. ${ }^{17-19}$ This kind of material is classified as "third generation, 20 and has attracted increasing attention in technical and research fields of gas adsorption, ${ }^{21,22}$ sensing, ${ }^{23}$ and structure 35 investigation. ${ }^{24,25}$

One strategy by which the transformations can be achieved uses ligands which form coordinating bonds of different binding strength. Once external stimulus is applied, the weaker bonds in the structure are more likely to be broken (and possibly reformed 40 on removal or change of the stimulus), resulting in changes of crystal structure. Meanwhile, the stronger coordinating bonds are more stable and strongly hold the whole framework so that the original structure can be recovered when the stimulus is stopped. One example of this strategy is the synthesis of $\mathrm{Cu}-\mathrm{SIP}-3$, a 45 copper 5 -sulfoisophthalate MOF that was reported by Xiao et $a l^{24,26,27}$. The ligand molecule, 5-sulfoisophthalate, contains one sulfonate and two carboxylate groups. The sulfonate group is weaker than the strongly binding carboxylate groups. Coordinated water molecules leave the copper atoms upon
50 dehydration and the sulfonate group changes its coordinating mode, resulting in a structural transformation of $\mathrm{Cu}-\mathrm{SIP}-3$. We have dubbed this type of material a 'hemilabile MOF' by analogy with homogenous catalysis where multidentate ligands can have different coordinating groups of varying strengths. This property ${ }_{55}$ of hemilability leads directly to an unusual property for $\mathrm{Cu}$-SIP3; ultraselectivity towards the adsorption of coordinating gases such as NO, which is particularly interesting because of NO's biological activity. ${ }^{28-30}$

In this paper, we report a new hemilabile MOF material that ${ }_{60}$ possesses the property of reversible single-crystal to singlecrystal transformation. The aim of the study was to show that targeted hemilabile MOFs can be prepared from ligands other than 5-sulfoisophthalate, and that the synthetic strategy may be general.

\section{Experimental}

All chemicals were commercially purchased and not further purified. $\mathrm{Cu}\left(\mathrm{NO}_{3}\right)_{2} \cdot 3 \mathrm{H}_{2} \mathrm{O}(0.242 \mathrm{~g}, 1 \mathrm{mmol})$, 2-sulfoterephthalic acid monosodium salt $(0.268 \mathrm{~g}, 1 \mathrm{mmol})$ and 4 , 4'-bipyridyl $70(0.156 \mathrm{~g}, 1 \mathrm{mmol})$ were dissolved in the mixed solvent of water $(7.2 \mathrm{~g}, 0.4 \mathrm{~mol})$ and ethanol $(9.2 \mathrm{~g}, 0.2 \mathrm{~mol})$. The solvent was stirring at room ambient condition for $15 \mathrm{~min}$ and transferred to a $50 \mathrm{ml}$ Teflon-lined autoclave. After heating at $383 \mathrm{~K}$ for 3 days, blue prism crystals were obtained. The products were filtered, 75 washed with distilled water and ethanol and dried at 343K. 0.274 $\mathrm{g}$ of 1 was obtained. (Yield of $90.7 \%$ (based on $\mathrm{Cu}$ ).)

Thermogravimetric analysis (TGA) was run in a Netzsch TG 209 instrument under the atmosphere of air. The sample was heated in aluminium crucible at a heating rate of $10 \mathrm{Kmin}^{-1}$. The hydrated ${ }_{80}$ crystals were filled in a glass capillary and laid in a Schlenk apparatus. According to the result of TGA, the dehydration was carried out at $503 \mathrm{~K}$ under vacuum. The colour of sample completely changed to dark green within 12 hours and gave the dehydrated sample. The capillary was quickly sealed under Ar to ${ }_{85}$ prevent the rehydration. The dehydrated sample was exposed to open air for 24 hours to give the rehydrated sample. All the powder diffraction data of hydrated, dehydrated and rehydrated samples were collected in a STOE diffractometer under $\mathrm{CuK} \alpha$ radiation in Debye-Scherrer mode. The elemental analysis on $\mathrm{C}$, ${ }_{90} \mathrm{H}, \mathrm{N}$ and $\mathrm{S}$ of the products was taken place on a Carlo Erba CHNS analyser. Single crystal data of the compound were 
collected at Station 11.3.1 of the Advanced Light Source, Lawrence Berkeley National Laboratory, using a wavelength of $\lambda$ $=0.7749 \AA$. A Bruker AXS APEXII diffractometer was used for data collection, and the corresponding Bruker AXS APEXII 5 software was used during data collection and reduction. Data of hydrated samples are collected at $150 \mathrm{~K}$ and dehydrated samples at $500 \mathrm{~K}$. Variation in crystal temperature was achieved via the cryostream with a ramp rate of $360 \mathrm{Kh}^{-1}$. All the structures were solved using direct method by the program SHELXS-97 and then 10 refined on $\mathrm{F}^{2}$ using SHELXTL-97 software. (Sheldrick, G. M. University of Gottingen, Germany, 1997.) Non-hydrogen atoms were refined anisotropically for hydrated structure. In the dehydrated structure, all carbon atoms were refined isotropically for a satisfactory refinement at high temperature. Other non-

15 hydrogen atoms of the dehydrated structure were refined anisotropically. Hydrogen atoms of the coordinated water molecules in the hydrated compound were fixed with DFIX restrains. Other hydrogen atoms were fixed based on idealized coordinates and refined with values of $\mathrm{U}_{\text {iso }}$ set to 1.2 times that of 20 the carrier atoms.

\section{Results and Discussion}

The materials were prepared from copper nitrate and two ligands; 2-sulfoterephthalate (STP), which contains one sulfonate group and two carboxylate groups, is used as the main ligand and 4, 4'25 bipyridine (Bpy) is used as an auxiliary ligand. After hydrothermal treatment at $383 \mathrm{~K}$ for 3 days in a water/ethanol mixed solvent the ligands coordinate to copper ions to form a novel 3-dimensional compound, $\quad \mathbf{C u}_{3}(\mathbf{S T P})_{2}(\mathbf{B p y}) \cdot \mathbf{4} \mathbf{H}_{2} \mathrm{O}$ (Compound 1).

30 Thermal gravimetric analysis (TGA) indicated a loss of coordinated guest molecules at about $473 \mathrm{~K}$ and powder X-ray diffraction (PXRD) showed the hydrated Compound 1 transformed to a crystalline dehydrated form, $\mathbf{C u}_{3}(\mathbf{S T P})_{2}(\mathbf{B p y})$ (Compound 2), after heating to $500 \mathrm{~K}$ under vacuum. The reverse

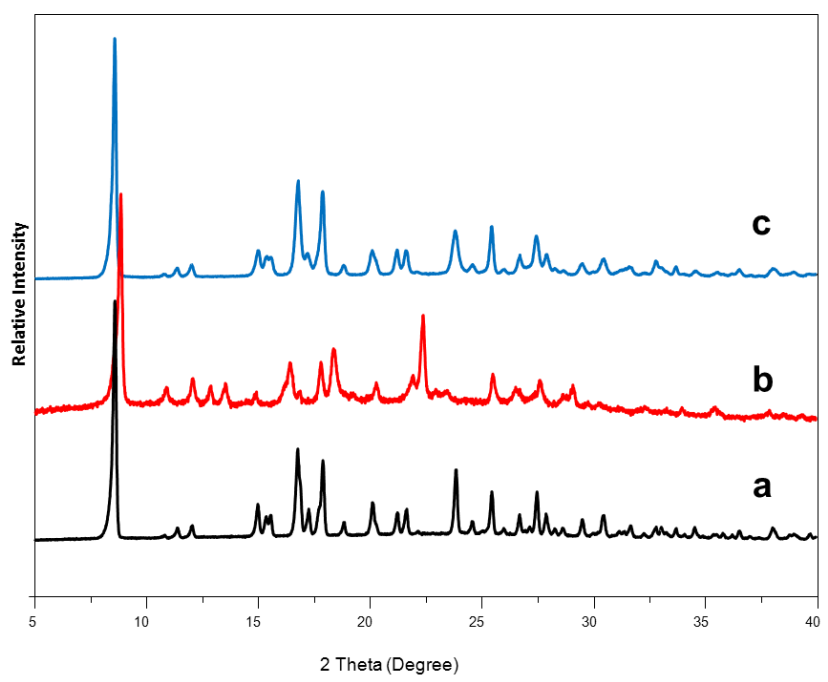

35 transformation between $\mathbf{2}$ and $\mathbf{1}$ was also verified by PXRD after rehydration (Figure 1).

Fig. 1 PXRD pattern of the crystal of (a) hydrated phase, (b) dehydrated phase and (c) rehydrated phase showing the changes in peak position on dehydration.

Variable temperature single-crystal X-ray analysis was used to 40 solve the structures of hydrated $\mathbf{1}$ and dehydrated $\mathbf{2}$. The result of variable temperature single-crystal X-ray analysis indicated the reversible single-crystal to single-crystal transformation is caused by the variable coordinating modes of the weaker sulfonate ligand to the metal ions (Scheme 1) and supports the synthetic 45 strategy. Full details of the synthesis and structural characterisation are in the supporting online information.

The TGA curve of 1 shows a weight loss of $7.42 \%$ ranging from $473 \mathrm{~K}$ to $513 \mathrm{~K}$ in air atmosphere. This weight loss corresponds to the removal of the coordinated molecules. The second step of ${ }_{50}$ weight loss started at about $543 \mathrm{~K}$ is considered to be the

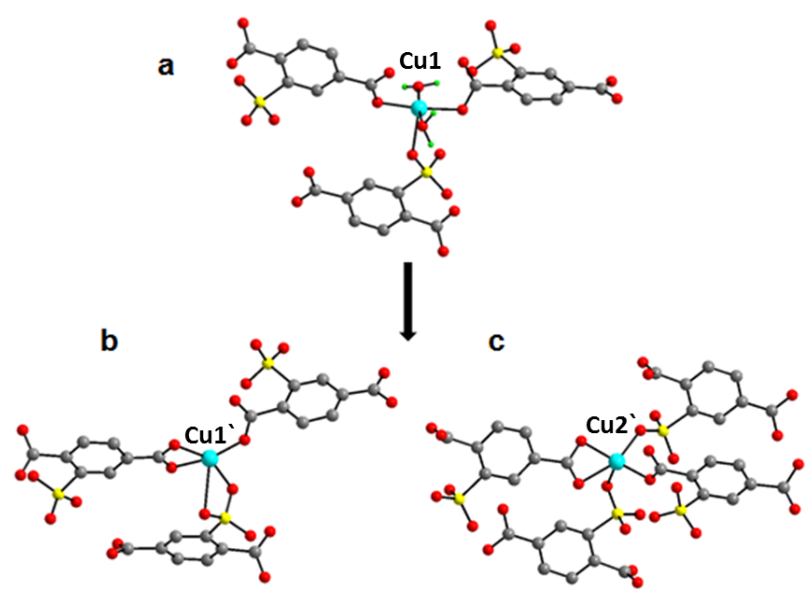

decomposition of organic ligands and the crystal starts to lose its crystallinity. (See Supporting information, Fig. S1.)

Fig.2 The coordination geometry of $\mathrm{Cu} 1$ in hydrated structure (a) and the changes of the geometries of $\mathrm{Cu} 1^{\prime}$ and $\mathrm{Cu} 2{ }^{\prime}$ after dehydration ( $\mathrm{b}$ and $\left.\mathrm{c}\right)$. (Cu: turquoise, $\mathrm{O}$ : red, 55 S: yellow, C: grey, H: green, only water hydrogen is present for clarity.)

To investigate the dehydrated material the sample was heated at $500 \mathrm{~K}$ under vacuum to investigate any structural change. The PXRD patterns of hydrated, dehydrated and rehydrated samples are shown in Fig. 1. The presence of the sharp peaks of the ${ }_{60}$ PXRD patterns indicates all the samples are crystalline. The changes of the pattern peaks of the dehydrated sample indicate that a structural rearrangement occurs (Fig. 1b). The sample is reversibly rehydrated when the dehydrated sample is exposed to the moist air, which is proved by the identical powder pattern of ${ }_{65}$ rehydrated sample to that of the hydrated one (Fig. 1c).

In order to characterize the structures of hydrated and dehydrated phases and the structural rearrangement between them, variable temperature single crystal X-ray analysis was carried out. Data collection of the dehydrated sample was at $500 \mathrm{~K}$.

70 The crystal structure of hydrated 1 contains two crystallographically independent copper atoms, one a 5coordinated $(\mathrm{Cu} 1)$ and one 6-coordinated $(\mathrm{Cu} 2)$. Each $\mathrm{Cu} 1$ atom is coordinated by three independent ligand molecules of STP and two water molecules (Fig. 2a). Three ligand oxygen atoms 75 coordinate to $\mathrm{Cu} 1$, one of which comes from a sulfonate group and the other two come from two individual carboxylate groups. The bond lengths of copper to carboxylate oxygen are 1.9912(16) $\AA$ and 1.9321(17) $\AA$ respectively. Compared to the $\mathrm{Cu}-\mathrm{O}(\mathrm{C})$ bond, the bond length of copper to sulfonate oxygen is $\mathrm{Cu} 1-\mathrm{O}(\mathrm{S})$ ${ }_{80}=2.2893(16) \AA$, consistent with the weaker binding of sulfonate to copper than that of carboxylate to copper. Similarly, the bond lengths of copper to water oxygen are 1.9758(16) $\AA$ and $1.9910(16) \AA$ so the binding strength of $\mathrm{Cu} 1$ to oxygen in $\mathbf{1}$ is 
likely to be in the order of $\mathrm{Cu} 1-\mathrm{O}(\mathrm{C})>\mathrm{Cu} 1-\mathrm{O}$ (water) $>\mathrm{Cu} 1-$ $\mathrm{O}(\mathrm{S})$. The $\mathrm{Cu} 2$ atoms are coordinated by two STP molecules and two Bpy molecules. Each STP molecule chelates to the $\mathrm{Cu} 2$ by one sulfonate oxygen and carboxylate oxygen. The distance of
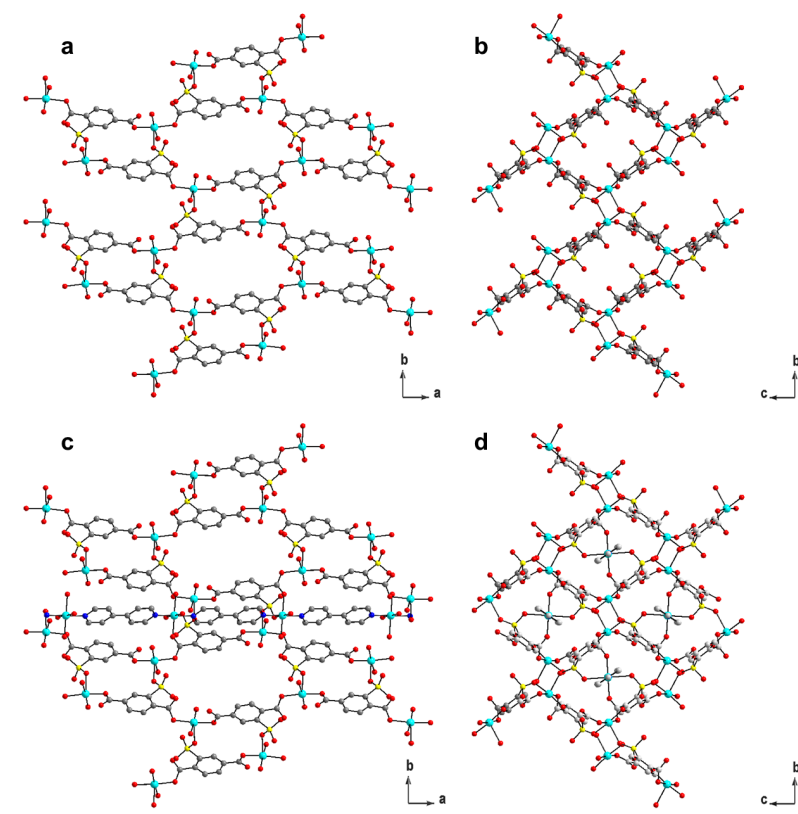

${ }_{5} \mathrm{Cu} 2$ to sulfonate oxygen is $2.2886(17) \AA$ and bond length of $\mathrm{Cu} 2-$ $\mathrm{O}(\mathrm{C})$ is $2.0433(16) \AA$.

Fig. 3.Structures of compound 1. (a) Infinite layer structure (view along $c$ axis) (b) The same layer viewed along $a$ axis. (c) One layer with a $\mathrm{Cu}-\mathrm{Bpy}-\mathrm{Cu}$ chain that penetrates through this layer. (view along $c$ axis) (d) One layer with four $\mathrm{Cu}-\mathrm{Bpy}-\mathrm{Cu}$ 10 chains penetrated through it. (view along $a$ axis). (Cu: turquoise, $\mathrm{O}$ : red, $\mathrm{S}$ : yellow, $\mathrm{C}$ : grey, N: blue. Hydrogen is not shown for clarity)

The overall crystal structure of hydrated compound $\mathbf{1}$ is shown in Fig. 3 and Fig. 4. Each $\mathrm{Cu} 1$ atom is coordinated by three surrounding STP ligands. A 2-dimensional layer structure is 15 formed by repeating these Cu1-STP connections (Fig. 3a and 3b). In addition to coordinating to the $\mathrm{Cu} 1$ atoms, each STP molecule also chelates to a $\mathrm{Cu} 2$ atom with one sulfonate and one carboxylate group. Every $\mathrm{Cu} 2$ atom is coordinated by two STP ligands that belong to two neighbouring layers. The $\mathrm{Cu} 2$ atoms 20 link each 2-D layers to a 3-dimensional structure. The adjacent $\mathrm{Cu} 2$ atoms in the same layer are linked by the 4, 4'-bipyridine molecule. The linear $\mathrm{Cu}-\mathrm{Bpy}-\mathrm{Cu}$ chains penetrate through the layer. Three layers and the $\mathrm{Cu}-\mathrm{Bpy}-\mathrm{Cu}$ chains are shown in Fig. 4 in different colours.

${ }_{25}$ After carefully heating, two coordinated water molecules are removed. Hydrated compound $\mathbf{1}$ transforms to its dehydrated phase of compound 2. An obvious change of the coordinating mode of the STP ligand is that one sulfonate group, which originally coordinated to two $\mathrm{Cu}$ atoms, now coordinates to three

${ }_{30} \mathrm{Cu}$ atoms (Scheme 1). The changes of coordination environment of $\mathrm{Cu} 1$ are shown in Fig. 2. In 2, four independent copper atoms are present. Two of them are originated from $\mathrm{Cu} 1$ of $\mathbf{1}$, denoted as $\mathrm{Cu} 1^{\prime}$ and $\mathrm{Cu} 2^{\prime}$. The coordination geometries of two copper atoms are shown in fig. $2 b$ and fig. $2 c$. Both of them are 535 coordinated. $\mathrm{Cu} 1^{\prime}$ is coordinated by three STP ligand molecules. One STP molecule provides a bidentate carboxylate group. Another STP provides a bidentated sulfonate group and the third STP keeps the same monodentated carboxylate group as $\mathrm{Cu} 1$ of
Compound 1. Three bond lengths of Cu1' to carboxylate oxygen 40 are 1.825(8) $\AA, 1.907(10) \AA$ and 1.948(9) $\AA$, respectively. One of the $\mathrm{Cu}{ }^{\circ}-\mathrm{O}(\mathrm{S})$ bond is $1.960(9) \AA$ long while the other bond is of 2.5354(116) $\AA$, indicating the weaker binding strength of this sulfonate oxygen. $\mathrm{Cu} 2{ }^{\prime}$ is coordinated by four STP molecules. One sulfonate group which was not coordinated to this copper in ${ }_{45}$ Compound 1 now monodentate to it and link the adjacent parallelogram unit together. A previously monodentate carboxylate coordinates to $\mathrm{Cu} 2{ }^{\prime}$ in a bidentate way. The bond lengths of $\mathrm{Cu} 2^{-}-\mathrm{O}(\mathrm{C})$ are $1.856(9) \AA, 1.869(12) \AA$ and 2.121(14) $\AA$. The bond lengths of $\mathrm{Cu} 2^{2}-\mathrm{O}(\mathrm{S})$ are $1.975(10) \AA$ and 2.193(10) ${ }_{50} \AA$ repeectively, the former being considerably shorter than the $\mathrm{Cu}-(\mathrm{O}) \mathrm{S}$ bond in the Compound 1 . The quite similar bond lengths of $\mathrm{Cu} 2^{-}-\mathrm{O}(\mathrm{C})$ and $\mathrm{Cu} 2^{-}-\mathrm{O}(\mathrm{S})$ indicate the sulfonate group strongly coordinate to metal site after removal of water. The other two crystallographically indendent copper atoms, denoted as ${ }_{55} \mathrm{Cu} 3{ }^{\prime}$ and $\mathrm{Cu} 4$, are originated from the $\mathrm{Cu} 2$ in Compound $\mathbf{1}$. Similar to $\mathrm{Cu} 2$, they are still 6-coordinated by two STP molecules and two Bpy molecules in an inverse way. However, the bond lengths of copper to sulfonate oxygen increase to 2.334(10) $\AA$ of $\mathrm{Cu} 3^{\prime}-\mathrm{O}(\mathrm{S})$ and $2.6635(92) \AA$ of $\mathrm{Cu} 4{ }^{\prime}-\mathrm{O}(\mathrm{S})$. Meanwhile the $\mathrm{Cu}-$
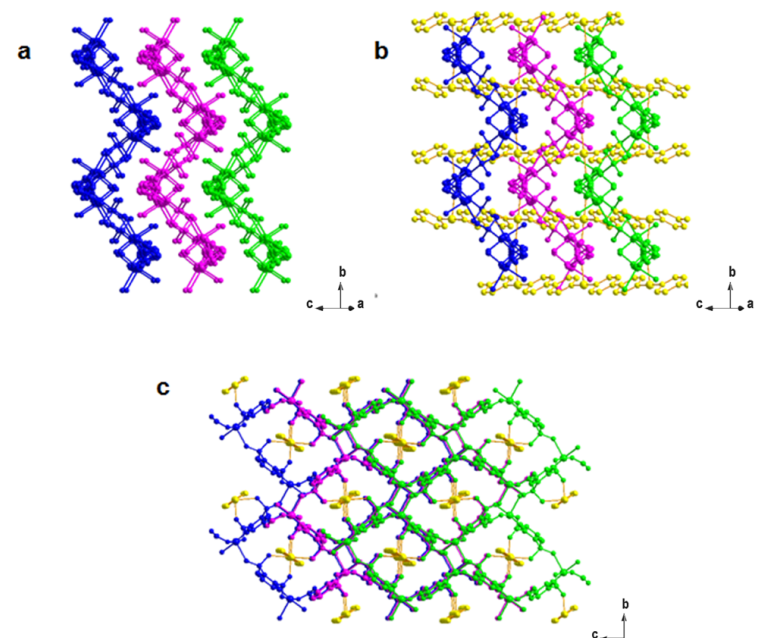

${ }_{60} \mathrm{Bpy}-\mathrm{Cu}$ chain is twisted. The angle between two pyridine plane is $19.131(821)^{\circ}$. (see Supporting Information)

Fig.4. (a) three adjacent infinite layers (blue, purple and green) and (b) $\mathrm{Cu}-\mathrm{Bpy}-\mathrm{Cu}$

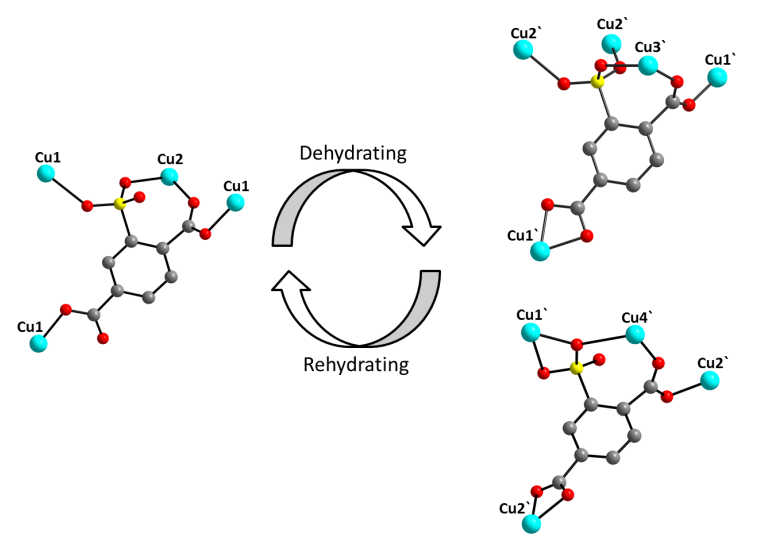

chains (yellow) penetrated through these layers. (c) Layer structures and the $\mathrm{Cu}-$ Bpy-Cu chains viewed along $a$ axis. 


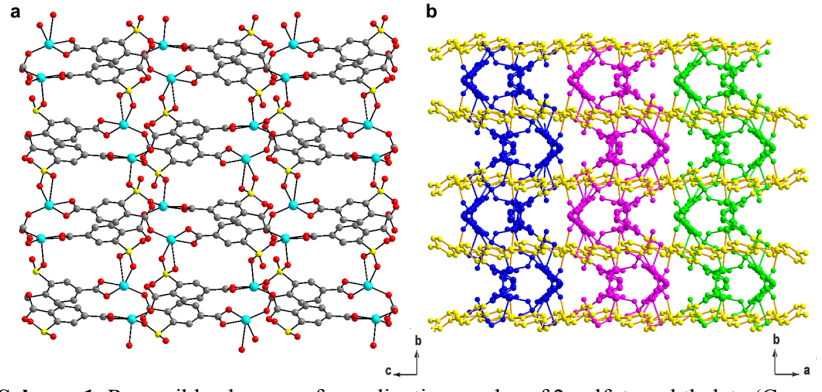

Scheme 1. Reversible changes of coordination modes of 2-sulfoterephthalate $(\mathrm{Cu}$ : turquoise, O: red, S: yellow, C: grey. Hydrogen on ligand is not shown for clarity)

Fig. 5 (a) Double layer structure of compound 2 viewed along $a$ axis. (Cu: turquoise, O: red, S: yellow, C: grey. Hydrogen is not shown for clarity) (b) crystal structure of 5 compound 2 view along $c$ axis. Three double layers are shown in cyan, purple and green. The $\mathrm{Cu}-\mathrm{Bpy}-\mathrm{Cu}$ chains are shown in yellow

A structural transformation is caused by the changes of the coordination mode of sulfonate groups. In compound $1, \mathrm{Cu} 1$ and STP molecules form a infinite 2-D layer. When it is dehydrated, 10 every $\mathrm{Cu} 2$ ' atom is coordinated by two sulfonate groups from the adjacent layers. In this case a double-layer structure is formed (Fig. 5a). The copper atoms on the $\mathrm{Cu}-\mathrm{Bpy}-\mathrm{Cu}$ chains link the double layers to a 3-D structure. The $\mathrm{Cu}-\mathrm{Bpy}-\mathrm{Cu}$ chains pass through the whole structure. (Fig. 5b)

\section{Conclusions}

To achieve a reversible single-crystal to single-crysta transformation of MOF materials, one synthetic strategy is to choose ligands that contain both weak and strong coordinating groups. Targeting this property, 2-sulfoterephthalate is selected as 20 an eligible ligand. A copper MOF compound is hydrothermally synthesized with this ligand and 4, 4'-Bipyridine. The assynthesized compound lost the coordinating water when heated above $473 \mathrm{~K}$ and a structural transformation occurred. The single crystal remains intact after dehydration so a variable temperature 25 single-crystal analysis is feasible. Single crystal X-ray diffraction and crystallography indicated the rearrangement of the coordination bonds, especially the coordination mode of sulfonate group to $\mathrm{Cu}$. In the hydrated compound, the $\mathrm{Cu}-\mathrm{O}$ bond lengths are in the order of $\mathrm{Cu} 1-\mathrm{O}(\mathrm{C})>\mathrm{Cu} 1-\mathrm{O}$ (water) $>\mathrm{Cu} 1-\mathrm{O}(\mathrm{S})$. After 30 dehydration, the sulfonate groups coordinated to the $\mathrm{Cu}$ which lost the coordinating water more strongly than before. Obvious decrease of bond length of $\mathrm{Cu}-\mathrm{O}(\mathrm{S})$ was observed. Though synthesis of metal organic framework with targeted property is still a challenge, dynamic transformation can be achieved by the 35 strategy of selecting ligands. This kind of materials is interested in selective gas adsorption, sensing and mechanism investigation. The work successfully demonstrates that the strategy of choosing ligands containing groups with varying coordination groups (e.g. those containing phosphonate groups ${ }^{31}$ or other unusual linkers in ${ }_{40}$ hybrid materials ${ }^{32}$ as well as sulfonate/carboxylate) is potentially a general strategy for the preparation of hemilabile MOFs.

\section{Acknowledgements}

Y. T. acknowledges the support from China Scholarship Council. ${ }_{45}$ R.E.M. is a Royal Society Industry Fellow and thanks the British Heart Foundation (NH/11/8/29253) and the EPSRC for support (EP/K005499/1 and EP/K025112/1). The Advanced Light Source is supported by the Director, Office of Science, Office of
Basic Energy Sciences, of the U.S. Department of Energy under ${ }_{50}$ Contract No. DE-AC02- 05CH11231.

\section{Notes and references}

${ }^{a}$ EaStChem School of Chemistry, University of St Andrews, Purdie Building, St Andrews KY16 9ST, UK. Fax: (+44) 1334-463-808 Prof. Russell E. MorrisE-mail: rem1@st-and.ac.uk

${ }_{55}{ }^{b}$ Department of Chemistry, College of Sciences, Shanghai University, Shanghai, China, 200444

$\dagger$ Electronic Supplementary Information (ESI) available: Cif files of hydrated compound 1(CCDC 941460) and dehydrated compound 2(CCDC 941461); details of experimental sections; results of elemental 60 analysis; PXRD pattern at different temperature; TGA curve and crystallographic data can be found in supporting information. See DOI: $10.1039 / \mathrm{b} 000000 \mathrm{x} /$

65 1. J. R. Long and O. M. Yaghi, Chem. Soc. Rev., 2009, 38, 1213-1214.

2. S. Kitagawa, R. Kitaura and S.-i. Noro, Angew. Chem. Int. Ed., 2004, 43, 2334-2375.

3. S. L. James, Chem. Soc. Rev., 2003, 32, 276-288.

4. L. J. Murray, M. Dinca and J. R. Long, Chem. Soc. Rev., 2009, 38, 1294-1314

5. R. E. Morris and P. S. Wheatley, Angew. Chem. Int. Ed., 2008, 47, 4966-4981.

6. A. C. McKinlay, R. E. Morris, P. Horcajada, G. Férey, R. Gref, P. Couvreur and C. Serre, Angew. Chem. Int. Ed., 2010, 49, 6260-6266.

7. P. Horcajada, T. Chalati, C. Serre, B. Gillet, C. Sebrie, T. Baati, J. F. Eubank, D. Heurtaux, P. Clayette, C. Kreuz, J.-S. Chang, Y. K. Hwang, V. Marsaud, P.-N. Bories, L. Cynober, S. Gil, G. Ferey, P. Couvreur and R. Gref, Nat Mater, 2010, 9, 172-178.

80 8. J.-R. Li, R. J. Kuppler and H.-C. Zhou, Chem. Soc. Rev., 2009, 38, 1477-1504.

9. H. Guo, G. Zhu, I. J. Hewitt and S. Qiu, J. Am. Chem. Soc., 2009, 131, 1646-1647.

10. Y.-S. Li, F.-Y. Liang, H. Bux, A. Feldhoff, W.-S. Yang and J. Caro, 85 Angew. Chem. Int. Ed., 2010, 49, 548-551.

11. J. Lee, O. K. Farha, J. Roberts, K. A. Scheidt, S. T. Nguyen and J. T. Hupp, Chem. Soc. Rev., 2009, 38, 1450-1459.

12. M. O'Keeffe, Chem. Soc. Rev., 2009, 38, 1215-1217.

13. M. Eddaoudi, J. Kim, N. Rosi, D. Vodak, J. Wachter, M. O'Keeffe $90 \quad$ and O. M. Yaghi, Science, 2002, 295, 469-472.

14. C. Serre, C. Mellot-Draznieks, S. Surblé, N. Audebrand, Y. Filinchuk and G. Férey, Science, 2007, 315, 1828-1831.

15. M. I. H. Mohideen, B. Xiao, P. S. Wheatley, A. C. McKinlay, Y. Li, A. M. Z. Slawin, D. W. Aldous, N. F. Cessford, T. Düren, X.

95 Zhao, R. Gill, K. M. Thomas, J. M. Griffin, S. E. Ashbrook and R. E. Morris, Nat Chem, 2011, 3, 304-310.

16. K. Uemura, R. Matsuda and S. Kitagawa, J. Solid State Chem., 2005, 178, 2420-2429.

17. J.-P. Zhang, Y.-Y. Lin, W.-X. Zhang and X.-M. Chen, J. Am. Chem. Soc., 2005, 127, 14162-14163.

18. E. Y. Lee and M. P. Suh, Angew. Chem. Int. Ed., 2004, 43, 27982801.

19. A. Aslani, A. Morsali and M. Zeller, Dalton Trans., 2008, 0, 51735177. 
20. S. Kitagawa and R. Matsuda, Coord. Chem. Rev., 2007, 251, 24902509.

21. X. Zhao, B. Xiao, A. J. Fletcher, K. M. Thomas, D. Bradshaw and M. J. Rosseinsky, Science, 2004, 306, 1012-1015.

5 22. K. Uemura, S. Kitagawa, M. Kondo, K. Fukui, R. Kitaura, H.-C. Chang and T. Mizutani, Chem. Eur. J., 2002, 8, 3586-3600.

23. Y. Qi, F. Luo, Y. Che and J. Zheng, Cryst. Growth Des., 2007, 8, 606-611.

24. P. K. Allan, B. Xiao, S. J. Teat, J. W. Knight and R. E. Morris, J. Am. $10 \quad$ Chem. Soc., 2010, 132, 3605-3611.

25. X.-Y. Wang, M. Scancella and S. C. Sevov, Chem. Mater., 2007, 19, 4506-4513.

26. P. K. Allan, K. W. Chapman, P. J. Chupas, J. A. Hriljac, C. L. Renouf, T. C. A. Lucas and R. E. Morris, Chem. Sci., 2012, 3, 2559-2564.

27. B. Xiao, P. J. Byrne, P. S. Wheatley, D. S. Wragg, X. Zhao, A. J. Fletcher, K. M. Thomas, L. Peters, S. O. EvansJohn, J. E. Warren, W. Zhou and R. E. Morris, Nat Chem, 2009, 1, 289294.

20 28. P. S. Wheatley, A. R. Butler, M. S. Crane, S. Fox, B. Xiao, A. G. Rossi, I. L. Megson and R. E. Morris, J. Am. Chem. Soc., 2005, 128, 502-509.

29. R. M. J. Palmer, A. G. Ferrige and S. Moncada, Nature, 1987, 327, 524-526.

25 30. R. F. Furchgott and J. V. Zawadzki, Nature, 1980, 288, 373-376.

31. (a) G. B. Hix, D. S. Wragg, P. A. Wright and R. E. Morris, Dalton Trans., 1998, 3359-3361; (b) V. J. Carter, P. A. Wright, J. D. Gale, R. E. Morris, E. Sastre and J. PerezPariente, J. Mater. Chem., 1997, 7, 2287-2292

30 32. D. S. Wragg, G. B. Hix and R. E. Morris, J. Am. Chem. Soc., 1998, 120, 6822-6823 